\title{
EDUCAÇÃO ESCOLAR INDÍGENA: TRAJETÓRIAS HISTÓRICAS E MOMENTO ATUAL NO BRASIL E NA BAHIA
}

\author{
Jucimar Pereira dos Santos ${ }^{1}$ \\ Maria Nazaré Mota de Lima²
}

\begin{abstract}
Resumo: O presente trabalho apresenta a trajetória histórica da educação escolar indígena do Brasil e da Bahia em seus aspectos mais significativos, numa perspectiva de enfatizar o processo de lutas advindas do Movimento Indígena Brasileiro a partir da década de 1970, imbricado com os pressupostos da história política, no estabelecimento de uma relação de poder e questões hierárquicas, assim como os desafios que os povos indígenas do Brasil e da Bahia têm vivenciado para garantir o direito a uma educação específica, intercultural, comunitária e diferenciada, de acordo com a legislação educacional pertinente a esta educação.
\end{abstract}

Palavras-Chave: educação escolar indígena — política educacional — direitos indígenas

\begin{abstract}
This paper presents the historical trajectory of indigenous education in Brazil and Bahia in its most significant aspects, with a view to emphasize the process of arising struggles of the Brazilian Indigenous Movement from the 1970s, interwoven with the assumptions of history policy, the establishment of a relationship of power and hierarchical issues, as well as the challenges that indigenous peoples of Brazil and Bahia has experienced to ensure in fact the right to a specific and differentiated education according to relevant educational legislation to this education.
\end{abstract}

Keywords: indigenous education — education politic — Indigenous rights

\section{INTRODUÇÃO}

As discussões acerca da educação escolar indígena no contexto da educação brasileira, nas últimas décadas, têm provocado reflexões em torno da legitimidade das lutas dos povos indígenas para garantia de seus direitos enquanto cidadãos brasileiros. Nessas trajetórias, encontra-se um cenário marcado por lutas históricas, fortalecimento das práticas escolares nas escolas indígenas e uma relação bastante íntima entre educação e cultura.

1 Pedagogo. Mestre em Crítica Cultural pela Universidade do Estado da Bahia (UNEB). Departamento de Educação II - Alagoinhas. Doutorando em História pela Universidade Vale do Rio dos Sinos (UNISINOS), São Leopoldo — RS. Endereço eletrônico: jucearp@gmail.com.

2 Professora da Universidade do Estado da Bahia (UNEB), Programa de Pós-Graduação em Crítica Cultural (Pós-Crítica); Coordenadora da Área de Linguagens e Artes na Licenciatura Intercultural em Educação Escolar Indígena (LICEEI-UNEB). Endereço eletrônico: librianar@gmail.com. 
Pontos de Interrogação, v. 4, n. 2, jul./dez. 2014

Revista do Programa de Pós-Graduação em Crítica Cultural

Universidade do Estado da Bahia (UNEB), Campus II — Alagoinhas — BA

Ao adentrar nas questões relacionadas à educação escolar indígena, é preciso começar por distinguir educação indígena e educação escolar indígena. Dessa forma:

Educação se define como o conjunto dos processos envolvidos na socialização dos indivíduos, correspondendo, portanto, a uma parte constitutiva de qualquer sistema cultural de um povo, englobando mecanismos que visam à sua reprodução, perpetuação e/ou mudança. Ao articular instituições, valores e práticas, em integração dinâmica com outros sistemas sociais, como a economia, a política, a religião, a moral, os sistemas educacionais têm como referência básica os projetos sociais (ideias, valores, sentimentos, hábitos etc.) que lhes cabem realizar em espaços e tempos sociais específicos. Assim, a educação indígena refere-se aos processos próprios de transmissão e produção dos conhecimentos dos povos indígenas, enquanto a educação escolar indígena diz respeito aos processos de transmissão e produção dos conhecimentos não indígenas e indígenas por meio da escola, que é uma instituição própria dos povos colonizadores. A educação escolar indígena refere-se à escola apropriada pelos povos indígenas para reforçar seus projetos socioculturais e abrir caminhos para o acesso a outros conhecimentos universais, necessários e desejáveis, a fim de contribuírem com a capacidade de responder às novas demandas geradas a partir do contato com a sociedade global (LUCIANO, 2006, p. 129).

Entendendo essa diferença, percebemos o que é educação escolar indígena para, a partir daí, compreender o processo de chegada da escola nas comunidades indígenas. Na maioria das vezes, não se aborda, nos meios acadêmicos, principalmente nos cursos de licenciatura, a história da educação escolar indígena, tema considerado de pouca ou nenhuma importância, nos limites de paradigmas eurocêntricos de educação, distantes do princípio da diversidade.

Outra questão importante refere-se aos modelos de educação. No processo de colonização do Brasil, na gênese da educação escolar indígena, Marilda do Couto Cavalcanti e Terezinha de Jesus M. Maher (2006) nos diz que Educação Escolar Indígena pode ser encaixada em dois paradigmas: o assimilacionista e o emancipatório. Na década de 70 foi predominante o paradigma assimilacionista. Segundo esse modelo de educação, a história e cultura indígena não contam, daí a necessidade de catequese, implicando a negação de valores, práticas culturais, línguas indígenas, conforme as autoras coloca no trecho a seguir:

Nesse paradigma, o que se pretende é, em última instância, educar o índio para que ele deixe de ser índio: o objetivo do trabalho pedagógico é fazê-lo abdicar de sua língua, de suas crenças e de seus padrões culturais e incorporar, assimilar os valores e comportamentos, inclusive linguísticos, da sociedade nacional. Inicialmente, tentou-se atingir tal objetivo através das orientações fornecidas pelo Modelo Assimilacionista de Submersão, onde as crianças indígenas eram retiradas de suas famílias, de suas aldeias e colocadas em internatos para serem catequizadas, para aprenderem português e os nossos costumes, enfim, para "aprenderem a ser gente". Porque o que se acreditava é que os costumes e crenças indígenas não correspondiam aos valores da modernidade (CAVALCANTI e MAHER, 2006, p. 19-20). 
Pontos de Interrogação, v. 4, n. 2, jul./dez. 2014

Revista do Programa de Pós-Graduação em Crítica Cultural

Universidade do Estado da Bahia (UNEB), Campus II — Alagoinhas — BA

Práticas como as descritas por Cavalcanti e Maher povoam a história da educação escolar indígena. Segundo estas autoras, há muita documentação escrita atestando que o índio era visto como um bicho, um animal que precisava urgentemente, de acordo com o projeto de construção da Nação Brasileira, ser "civilizado", "humanizado", e à escola cabia levar a cabo tal incumbência, através de programas de submersão cultural e linguística. Assim, surgiu o Modelo Assimilacionista de Transição, no contexto da educação escolar indígena. Nesse modelo:

Não há a retirada da criança indígena do seio familiar. Antes, cria-se uma escola na aldeia e a língua de instrução, nas séries iniciais, é a língua indígena, porque, percebeu-se, é extremamente difícil alfabetizar uma criança em uma língua que ela não domina. Mas, nesse modelo, depois que a criança é alfabetizada em sua língua materna, depois que ela entende o que é a escrita, como é o seu funcionamento, vai-se introduzindo o português paulatinamente até que a língua indígena seja totalmente excluída do currículo escolar. A função da língua indígena é apenas servir de elemento facilitador para a aprendizagem de língua portuguesa, a qual, tendo sido aprendida, passará a ser a língua de instrução na apresentação dos demais conteúdos escolares (CAVALCANTI e MAHER, 2006, p. 21).

Seria então essa forma de educar as crianças indígenas?

É lamentável que experiências dessa natureza acontecessem em nosso Brasil, principalmente entre os povos indígenas das regiões Norte e Centro-Oeste, em um tempo não muito distante do nosso, pois esse cenário era os anos 70, quase final do século XX. Com o passar dos tempos, já nos anos 80 e ainda citando Cavalcanti e Maher (2006, p. 22), vemos que:

\begin{abstract}
Nos últimos vinte anos, pudemos presenciar uma modificação importante no cenário da Educação Escolar Indígena, com a introdução de um novo paradigma, o Paradigma Emancipatório, que sob seus princípios é construído o Modelo de Enriquecimento Cultural e Linguístico. Nele, o que se quer promover é um bilinguismo aditivo: pretende-se que o aluno indígena adicione a língua portuguesa ao seu repertório linguístico, mas pretende-se também que ele se torne cada vez mais proficiente na língua de seus ancestrais. Para tanto, insiste-se na importância de que a língua de instrução seja a língua indígena ao longo de todo o processo de escolarização e não apenas nas séries iniciais. Além disso, esse modelo busca promover o respeito às crenças, aos saberes e às práticas culturais indígenas.
\end{abstract}

Essas práticas dentro deste Paradigma Emancipatório têm influenciado a educação escolar indígena nos dias atuais, sendo esta a política de desenvolvimento de projetos voltados para as escolas indígenas adotadas por muitas instituições governamentais e nãogovernamentais, favorecendo o fortalecimento das práticas escolares das escolas indígenas, cada vez mais abandonando-se o paradigma assimilacionista, proposto e praticado desde o século XVI, voltado para a catequização dos povos indígenas, que se reapresenta na década de 70, como vimos anteriormente, enquanto modelo educacional onde o índio é "convidado a deixar de ser índio". 
Em contrapartida, a luta dos povos indígenas no Brasil de hoje é justamente para se ter uma educação escolar indígena construída e pensada pelos próprios índios, evitando, desta forma, uma nova "invasão", pois de acordo com os fundamentos gerais da educação escolar indígena contidos no RCNEI (2005), propõe-se o reconhecimento da multietnicidade, pluralidade e diversidade:

O Brasil é uma nação constituída por grande variedade de grupos étnicos, com histórias, saberes, culturas e, na maioria das situações, línguas próprias, onde tal diversidade sociocultural é riqueza que deve ser preservada (BRASIL, 2005, p. 22).

Reconhece a relação que existe entre educação e conhecimentos indígenas: desde muito antes da introdução da escola, os povos indígenas vêm elaborando, ao longo de sua história, complexos sistemas de pensamento e modos próprios de produzir, armazenar, expressar, transmitir, avaliar e reelaborar seus conhecimentos e suas concepções sobre o mundo, o homem e o sobrenatural (Idem, p. 22).

Para se ter uma ideia acerca da presença indígena no país e no estado da Bahia, recortando informações bem genéricas em relação à educação escolar, trazemos algumas informações sobre o universo de que tratamos neste texto, a partir de fontes oficiais consultadas.

A população indígena é de 810.000 , tomando como base os dados do IBGE/2010 ${ }^{3}$. Terras indígenas são 634; etnias 236, línguas indígenas 180, aldeias 3.487, municípios 367 e Estados da Federação 26. No Estado da Bahia, a população indígena é de 11.677, distribuídos em 14 povos, totalizando 76 aldeias e 24 municípios. (FUNAI — DF, 2011) ${ }^{4}$

No tocante à educação, na Bahia existem 59 escolas; dessas, 25 pertencem ao Sistema Estadual de Ensino e 34 ao Sistema Municipal de Ensino. 7.730 é o número total de estudantes, sendo 944 da Educação Infantil, 3.882 de $1^{\text {a }}$ a $8^{\text {a }}$ série, 303 do Ensino Médio, 903 na Educação de Jovens e Adultos, de acordo com informações da Secretaria da Educação do Estado da Bahia/Coordenação Estadual de Educação Escolar Indígena, ano de referência 2011. ${ }^{5}$

Conforme proposto, trata-se de uma educação que visa fortalecer os conhecimentos e culturas indígenas, assim como possibilitar a troca de experiências entre os povos e a salvaguarda do patrimônio material e imaterial das populações indígenas. A educação escolar indí-

3 Dados do IBGE 2010.

4 Dados FUNAI Brasília/2011.

5 Dados informados pela Coordenação Estadual de Educação Escolar Indígena - CIN/Secretaria da Educação do Estado da Bahia, 2011. 
gena adentra as primeiras décadas do século XXI, trazendo em seu bojo o contínuo processo de luta por uma educação específica, intercultural, comunitária e diferenciada, pautando a necessidade de uma política educacional comprometida com os projetos societários desses povos.

Os anos 90 foram marcados por conquistas significativas a respeito da educação escolar, no Brasil e na Bahia.

Tais conquistas ocorreram por conta da mobilização do movimento indígena organizado, advindo da década de 70 e que, após a redemocratização do Brasil na década de 80, passa a conquistar mais espaço, dando maior visibilidade ao que se propõe, continuando em seu processo de luta.

Com o Ministério da Educação - MEC assumindo a política da Educação Escolar Indígena no Brasil, criando no âmbito deste órgão governamental uma Coordenação Nacional de Escolar Indígena, dialogando com estados e municípios, uma política pública de educação escolar indígena começa a dar os primeiros passos. Dentro deste cenário, encontram-se experiências bem sucedidas de projetos de educação escolar indígena desenvolvidos em vários estados brasileiros. Mas, em contraponto, temos um viés da ideologia neoliberal presente na política educacional do MEC, através de programas destinados à educação básica, principalmente no que concerne à formação de professores. Um exemplo de políticas dessa natureza envolvendo professores indígenas é Parâmetros em Ação, desenvolvidos em parceria com as Secretarias Estaduais e Municipais de Educação.

O referido programa tinha como metodologia a formação de professores em todos os níveis e modalidades de ensino, através de materiais organizados por especialistas das diversas áreas de conhecimento, mas sem a participação dos seus beneficiários, os professores. Estes participavam dos encontros executando atividades, que já vinham "prontas", para serem aplicadas pelos coordenadores de cada polo de capacitação, pois o objetivo era implementar a proposta dos PCN distribuídos pelo MEC a todos os professores brasileiros em meados da década de 90. 
Especificamente em relação à educação escolar indígena foi organizado o documento Referencial Curricular Nacional para a Educação Indígena - $\mathrm{RCNEI}^{6}$, que contou com a colaboração de professores indígenas, especialistas e professores universitários de todo o Brasil. Este documento trouxe, de forma sistematizada, os princípios da educação escolar indígena, traduzindo em fundamentos gerais, bem como um breve histórico da educação escolar indígena no Brasil, orientações pedagógicas e orientações curriculares, organização do trabalho escolar e os temas transversais. Além disso, o referencial contém orientações metodológicas por área de conhecimento a ser trabalhada nas escolas indígenas: Línguas, Matemática, História, Geografia, Ciências, Arte e Educação Física.

O MEC, através da Coordenação Geral de Educação Escolar Indígena - CGEEI, disponibilizou para todas as Secretarias Estaduais de Educação que tinham escolas indígenas o referido documento impresso, para que fosse utilizado, inclusive nos cursos de formação de professores indígenas. Neste caso, o Curso de Magistério Indígena, além de disponibilizar outros materiais (guias para os coordenadores e para os cursistas, fitas de vídeo com os programas referentes a cada Unidade a ser estudada e caderno de anotações do percurso) que faziam parte dos Parâmetros em Ação para as escolas indígenas, disponibilizou o RCNEI, trabalhando-o no mencionado curso de formação de professores indígenas.

No Estado da Bahia, estávamos na etapa final da $1^{\text {a }}$ Turma do Magistério Indígena; o Parâmetros em Ação foi desenvolvido de forma parcial. Uma das críticas que se faz a este material é que ele chegou às escolas indígenas de forma vertical, impositiva, sem envolvimento de professores indígenas e suas comunidades, sem diálogo. Os professores tiveram acesso a esse material em momentos esporádicos; mas, de que forma as práticas de sala de aula são de fato vistas, percebidas dentro dessa proposta de trabalho, levando em conta toda a diversidade da educação escolar indígena no contexto brasileiro? Daí a crítica em relação aos Parâmetros em Ação, considerado pelos professores indígenas como um documento "pronto" a ser apenas

6 Este documento foi publicado pelo Ministério da Educação - MEC, no ano de 1997/1998, sob a Coordenação Geral de Educação Escolar Indígena do referido MEC e, mesmo trazendo os fundamentos gerais da educação escolar indígena, é um documento construído em um viés de uma educação neoliberal, política adotada pelo MEC no Governo Fernando Henrique Cardoso e no do Ministro Paulo Renato. O RCNEI, como é conhecido pelos professores indígenas, teve uma participação expressiva desses(as) professores(as), mas isso não significa que a sua linha ideológica seja, de fato, a desejada pelos Povos Indígenas do Brasil. 
Pontos de Interrogação, v. 4, n. 2, jul./dez. 2014

Revista do Programa de Pós-Graduação em Crítica Cultural

Universidade do Estado da Bahia (UNEB), Campus II — Alagoinhas — BA

seguido pelos professores indígenas, especialistas e técnicos das Secretarias estaduais e municipais de educação.

\section{A EDUCAÇÃO ESCOLAR INDÍGENA E A GARANTIA DOS DIREITOS NA LEGISLAÇÃO}

Outros documentos que estabelecem as diretrizes e os princípios da educação escolar indígena no país foram elaborados. O RCNEI foi do ano de 1997/1998 mas, em anos anteriores, tivemos o Decreto Presidencial n 26 do ano de 1991, que transfere a responsabilidade da educação indígena da FUNAI para o MEC, dando o primeiro passo para um amplo processo de descentralização das ações da educação escolar indígena, até então desenvolvidas exclusivamente pela FUNAI. Com esse Decreto, as ações passam a ser desenvolvidas pelo Ministério da Educação. A Portaria Ministerial n ${ }^{\circ} 559$ de 1991 cria no MEC uma Coordenação Nacional de Educação Indígena, e o seu Artigo $4^{\circ}$ diz que essa Coordenação Nacional é constituída por Técnicos do MEC e Especialistas de órgãos governamentais e não-governamentais afetam a educação indígena e universidades, com a finalidade de coordenar, acompanhar e avaliar as ações pedagógicas da educação indígena no país. Com isso, ampliam-se as discussões acerca da educação escolar indígena e as possibilidades de implementação de políticas de formação de professores indígenas e de produção de material didático específico, fundamentais para que às escolas indígenas sejam garantidos os direitos conquistados a partir da Constituição de 1988.

A Lei de Diretrizes e Bases da Educação Nacional — Lei no 9.394/96 nos seus Artigos 26, 32, 78 e 79 procura dar "corpo" ao que a Constituição de 1988 determina para os Povos Indígenas do Brasil, em termos do direito a uma educação específica e diferenciada, na perspectiva de garantir processos próprios de aprendizagem. Não dá para esquecer, porém, que a LDB, em 2011, foi alterada, a fim de estabelecer a obrigatoriedade de ensino da história e cultura indígenas nas escolas do país, incidindo, inclusive, sobre artigos citados acima.

Em 1999, ocorre a aprovação do Parecer 14/99 pelo Conselho Nacional de Educação — CNE/CEB, importante documento que traz em seu bojo o processo histórico da educação escolar indígena no Brasil, com avanços e retrocessos, sendo que a publicação do referido Parecer já pode ser considerado um grande avanço, uma vez que, na História da Educação Brasileira e suas políticas educacionais aparece um texto oficial falando da existência de escolas 
indígenas, sua organização política, curricular e pedagógica e, consequentemente, as Diretrizes Curriculares Nacionais para as Escolas Indígenas - Resolução 03/99, que materializa o que o Parecer 14/99 apresenta em seu texto.

No ano de 2001, a Lei $n^{\circ}$ 10.172/2001 estabelece o Plano Nacional de Educação PNE e, das 295 metas, 21 são da modalidade educação escolar indígena. No ano seguinte, 2002, o MEC publica os Referenciais para a Formação de Professores Indígenas, com o objetivo de orientar todos os Estados da Federação que possuem Povos Indígenas na oferta de cursos de formação inicial e continuada para professores indígenas.

Neste contexto, destaca-se o Decreto Presidencial $n^{\circ} 5.051$ de 2004, que promulga a Convenção 169 da Organização Internacional do Trabalho — OIT, um instrumento internacional que trata especificamente dos direitos dos povos indígenas e tribais no mundo. Mais recentemente, o Decreto Presidencial nº 6861/2009 cria os Territórios Etnoeducacionais, apresentando uma nova forma de gestão da educação escolar indígena no âmbito do Território Brasileiro, através das Políticas Educacionais do Ministério da Educação para os Povos Indígenas. O Parecer $n^{\circ} 13 / 2012$, do CNE/CEB, elucida o protagonismo dos professores indígenas em vários espaços de atuação, avança nas discussões acerca dos aspectos gerais da educação escolar indígena, entre eles a realização da I Conferência Nacional de Educação Escolar Indígena e das novas Diretrizes Curriculares Nacionais para a Educação Escolar Indígena.

No Estado da Bahia, o Decreto no 8.471 de 12 de março de 2003 do Governador do Estado cria a categoria Escola Indígena no âmbito do Sistema Estadual de Ensino da Bahia, e a Resolução $n^{\circ}$ 106/2004, do Conselho Estadual de Educação - CEE/BA, estabelece diretrizes e procedimentos para a organização e oferta da educação escolar indígena no Sistema Estadual de Ensino. Já a Lei Estadual nº 18.629/10, cria a carreira de professor indígena no Estado da Bahia.

Analisando esta trajetória em relação à legislação específica para a educação escolar indígena, percebe-se que as leis foram criadas, aprovadas pelos órgãos competentes mas, na prática, no chão da escola e da aldeia, existe um hiato muito grande entre o que estabelecem as leis e o que se concretiza no cotidiano das escolas e das comunidades. As reivindicações dos povos indígenas continuam de forma incisiva, e entendemos essas reivindicações como uma luta legítima desses povos, em fazer valer o direito que é prescrito nessas leis, por exemplo. 
Nobre (2005, p. 8), em seu texto Para uma síntese dos avanços e o escolar indígena hoje, situa alguns dos impasses que persistem, apesar dos avanços conquistados:

\begin{abstract}
Os impasses que permanecem: ausência de políticas linguísticas; descoordenação entre as políticas públicas indigenistas; dificuldades nos processos de reconhecimento e regularização das escolas indígenas; implantação de turmas de $5^{\mathrm{a}}$ a $8^{\mathrm{a}}$ séries e ensino médio nas escolas indígenas; manipulação dos Conselhos Municipais de Educação; má distribuição dos recursos do FUNDEB; ausência de mecanismos de controle social das políticas públicas; dificuldade de transporte escolar, limites da legislação; incipiente qualificação profissional dos técnicos das secretarias estaduais e municipais e não aplicação dos programas educacionais específicos federais à escola indígena.
\end{abstract}

Essas questões apontadas por Nobre (2005) têm sido uma constante nas escolas indígenas, não só em termos do contexto nacional, como também repercutindo no contexto estadual e local. Os órgãos públicos responsáveis pela educação escolar indígena, do ponto de vista nacional e local, têm conhecimento dessa situação, mas infelizmente pouco ou nada fazem, as questões burocráticas sobressaem no atendimento à demanda existente.

Os impasses para a efetivação de uma política de atendimento à educação escolar indígena no Brasil e na Bahia têm sido enormes, e muitas das reivindicações dos povos indígenas em relação à educação se constituem na pauta dos representantes indígenas, através de associações, conselhos, fóruns, quando esses representantes participam de encontros com autoridades municipais, estaduais e federais.

Quando se observam os dados da educação escolar indígena, tanto em nível de Brasil, quanto de Bahia, apesar de todas as dificuldades, sobressai um crescimento significativo de matrícula em todas as séries e modalidades de ensino. No cenário nacional, a educação escolar indígena apresenta os seguintes dados, segundo informações do MEC/CGEEI ${ }^{7}$, ano base 2010: nesse ano o Brasil tinha 2.836 escolas indígenas; 10.923 professores indígenas; 196.075 estudantes, sendo 19.565 na Educação Infantil, 109.919 de $1^{\mathrm{a}}$ a $4^{\mathrm{a}}$ série, 41.241 de $5^{\mathrm{a}}$ a $8^{\mathrm{a}}$ série, 10.004 no Ensino Médio e 15.346 na Educação de Jovens e Adultos — EJA.

Esses dados foram informados pelo Prof. Dr. Gersem dos Santos Luciano, pertencente ao Povo Baniwa e Coordenador Geral de Educação Indígena do Ministério da Educação - MEC/Brasília, durante a I Etapa do Curso de Formação para Gestores Indígenas, em Salvador - Bahia, no período de 03 a 07 de agosto de 2011. 


\section{ALGUMAS AÇÕES SINALIZAM AVANÇOS NA EDUCAÇÃO ESCOLAR INDÍGENA}

Muitos são os desafios, como mencionado anteriormente, mas muitos avanços também podem ser visualizados na educação escolar indígena em tempos mais recentes no Brasil e, especificamente, na Bahia. Aqui, trazemos três ações das quais participamos e que consideramos enquanto marcos importantes, por sua capacidade de se desdobrar em outras ações necessárias ao avanço das conquistas no movimento por educação escolar indígena e por pretenderem estar voltadas para a melhoria dessa educação, em consonância com os anseios e busca dos povos para que ela seja específica, intercultural, comunitária e diferenciada.

Um dos espaços de discussão envolvendo povos indígenas em todo o Brasil foi a I Conferência Nacional de Educação Escolar Indígena - CONEEI, que aconteceu no ano de 2009, no período de 16 a 21 de novembro, em Luziânia - Goiás. A I CONEEI foi realizada pelo MEC, em parceria com o Conselho Nacional de Secretários de Educação — CONSED e Fundação Nacional do Índio - FUNAI, focalizando o tema "Educação Escolar Indígena: gestão territorial e afirmação cultural". Para a realização dessa conferência, ocorreram, em todo o Brasil, em período anterior, conferências regionais refletindo sobre o tema da CONEEI, envolvendo representantes de órgãos governamentais, não governamentais, escolas indígenas e universidades, dentre outros.

Durante a realização da I CONEEI, um dos pontos discutidos foi o Decreto Presidencial $n^{\circ}$ 6.891, de 27 de maio de 2009, que dispõe sobre a Educação Escolar Indígena, define sua organização em Territórios Etnoeducacionais — TEE.

De acordo com o MEC, os TEE têm como objetivo organizar a educação escolar indígena, observando a sua territorialidade, por meio do Regime de Colaboração entre os Sistemas de Ensino e os Povos Indígenas, abrangendo todas as escolas indígenas e todo o território nacional.

O Estado da Bahia integra o Território Etnoeducacional — TEE Yby Yara que, em tupi, quer dizer "dono da terra". O TEE Yby Yara abrange todos os 14 povos indígenas da Bahia, sendo que a partir da criação deste TEE, toda a política de atendimento à educação escolar indígena no âmbito do estado, pactuado com os municípios, passa a ser através de um plano de ação elaborado com a participação de representantes indígenas, universidades, Secretaria 
Pontos de Interrogação, v. 4, n. 2, jul./dez. 2014

Revista do Programa de Pós-Graduação em Crítica Cultural

Universidade do Estado da Bahia (UNEB), Campus II — Alagoinhas — BA

da Educação do Estado da Bahia, Secretarias Municipais de Educação, MEC, FUNAI, UNDIME, Associações Indígenas.

Outro espaço importante que foi criado no contexto da educação escolar indígena no Brasil foi o Observatório da Educação Escolar Indígena, coordenado pela Coordenação de Aperfeiçoamento de Pessoal de Ensino Superior - CAPES. De acordo com a CAPES, o objetivo do Observatório da Educação Escolar Indígena é fomentar o desenvolvimento de estudos e pesquisas em educação que explorem ou articulem as bases de dados do INEP, visando estimular a produção acadêmica e a formação de recursos pós-graduados (mestrado e doutorado) e fortalecer a formação de profissionais da educação básica intercultural indígena, professores e gestores, para os Territórios Etnoeducacionais.

Na Bahia, o Observatório da Educação Escolar Indígena está sob a coordenação da Universidade Federal da Bahia - UFBA, envolvendo pesquisadores indígenas e não indígenas dos cursos de mestrado e doutorado da própria UFBA, da Licenciatura em Educação Escolar Indígena da Universidade do Estado da Bahia - LICEEI/UNEB e de outras instituições. As ações desenvolvidas no âmbito do Observatório da Educação Escolar Indígena na Bahia ${ }^{8}$ têm contribuído de forma significativa para o incremento de políticas públicas para os povos indígenas da Bahia, principalmente no que diz respeito à pesquisa da situação da Educação Escolar Indígena no Estado da Bahia, a partir de um diagnóstico muito bem detalhado e que tem subsidiado estudos e pesquisas, bem como atividades concernentes às escolas indígenas no estado.

A outra ação digna de nota, sobre a qual trazemos breve notícia, é a formação de professores/as realizada pela Licenciatura Intercultural em Educação Escolar Indígena (LICEEI), da UNEB. A LICEEI, na Bahia, começou suas atividades em 2009, envolvendo 109 profess ores indígenas de diversas etnias, já atuando em escolas indígenas. Os professores formadores são da UNEB e/ou de outras universidades, com experiência anterior na formação de professores indígenas, conforme Messeder (2013).

8 “2010 — diagnóstico pioneiro da situação educacional dos povos indígenas no Estado da Bahia, a partir de informações coletadas por professores/pesquisadores em suas aldeias, além de contar com linguísticas, antropólogos, historiadores e cientistas políticos indígenas e não indígenas”. SILVA, Carlos Rafael. O Modelo de Gestão Territorializada da Politica de Educação Escolar Indígena no Estado da Bahia. Revista Cadernos de Arte e Antropologia. [on-line]. Vol. 2. N. 2. 2013. Salvador - Bahia. Disponível na Internet: < http://www.cadernosaa.revues.org> ISSN Eletrônico 2238-036. Acesso em 15 de dezembro de 2014 
O curso possui uma concepção político-pedagógica exemplar, que se aperfeiçoa ao longo desses anos, a partir da sua execução que privilegia a interlocução com os professores indígenas e suas lideranças. No momento atual, incorpora professores indígenas pós-graduados como professores formadores - um avanço - e enfrenta sérios problemas de natureza administrativo-financeira que obstaculizam a realização de etapas previstas, conforme planejado.

Apesar das complicações que um curso desta natureza provoca em uma estrutura universitária ainda não adequada, é louvável o acolhimento da proposta e os investimentos de toda ordem que professores, coordenadores, estudantes, parceiros, administradores fazem, cotidianamente, para que se realize essa experiência intercultural.

\section{ALGUMAS CONSIDERAÇÕES}

Os caminhos para a educação escolar indígena implicam perspectivas de autonomia das escolas indígenas, em todos os sentidos, de modo a fortalecer o paradigma emancipatório, ainda ameaçado por um modelo de educação compulsória, que reproduz perspectivas conservadoras, positivistas e neoliberais, hegemônicas na educação escolar no Brasil.

Assim, considerando-se os avanços na legislação e nas ações e políticas em curso, apesar dos grandes desafios e impasses, é possível vislumbrar novos rumos, novas trajetórias da educação escolar indígena no Brasil e na Bahia. Nesse movimento, os povos indígenas cada vez mais se encontram fortalecidos e determinados em suas lutas pelo direito à educação escolar indígena específica, intercultural, comunitária e diferenciada, construída a partir de processos próprios de aprendizagem, de forma criativa e comprometida com os projetos e anseios de cada povo. Dessa maneira, seguem uma trajetória em que partilham saberes e conhecimentos e defendem que as práticas pedagógicas e os currículos nasçam a partir do chão da escola, da aldeia, desmobilizando práticas opressoras e excludentes que foram impostas tempos atrás pelo colonizador e que, em pleno século XXI, ainda persistem.

Neste cenário de embates, conquistas e lutas, emerge a beleza das trajetórias que se constrói no encontro com o outro, com a outra, no enraizamento do modo único de ser, "sendo índio".

Fica evidente ainda, nesse processo, que as trajetórias históricas percorridas pelos/as professores/as indígenas brasileiros/as, desde a década de 1970 do século passado até os dias 
atuais, têm servido para a materialização de seus projetos educacionais, voltados para o fortalecimento de sua cultura e de seu pertencimento enquanto povos tradicionais, e isso tem se traduzido a partir da ampliação da oferta educacional nas aldeias contemplando toda a educação básica (educação infantil, ensino fundamental, ensino médio) e todas as modalidades, assim como da oferta de cursos superiores para os professores/as indígenas.

\section{REFERÊNCIAS}

BRASIL, Ministério da Educação. Educação Escolar Indígena: Gestão Territorial e Afirmação Cultural. I Conferência Nacional de Educação Escolar Indígena. Documentos Referenciais. Brasília: 2008

BRASIL. CNE/Ministério da Educação. Diretrizes Curriculares Nacionais para a Educação Escolar Indígena. Resolução 03/1999 CNE/Ministério da Educação. Parecer de 14 de abril de 1999.

BRASIL. Constituição da República Federativa do Brasil. Brasília, 1998

BRASIL. Lei de Diretrizes e Base da Educação Nacional. Lei no 9394/1996. Brasília 1996

BRASIL. Ministério da Educação. Diretrizes para a Política Nacional de Educação Escolar Indígena. Brasília: MEC-SEF. Comitê Nacional de Educação Escolar Indígena, 1993

BRASIL. Ministério da Educação. Referencial Curricular Nacional para as escolas indígenas. Brasília: MEC, 1988

BRASIL. Ministério da Educação. Referencial para a formação de professores indígenas. Brasília: MEC 2004

BRASIL.CNE/Ministério da Educação. Parecer de 13 de maio de 2012.

CAVALCANTI, Marilda do Couto; MAHER, Terezinha de Jesus M. $O$ índio, a leitura e a escrita: o que está em jogo? Campinas: CEFIEL/UNICAMP/MEC, 2005.

LUCIANO, Gersem dos Santos. O índio brasileiro: o que você precisa saber sobre os povos indígenas no Brasil de hoje. MEC/LACED/Museu Nacional. 2006.

MESSEDER, Marcos Luciano. A construção da licenciatura indígena da UNEB: os dilemas, os desafios, os limites e as possibilidades. In CESAR, América; COSTA, Suzane (orgs.). Pesquisa e escola: experiências em educação indígena na Bahia. Salvador, Bahia: Quarteto, 2013, p. 37-54.

NOBRE, Domingos. Para uma síntese dos avanços e impasses da educação escolar indígena hoje. In: VEIGA, Juracilda; FERREIRA, Maria Beatriz Rocha (Org.). Desafios atuais da educação escolar indígena. Campinas, SP: ALB, Núcleo de Cultura e Educação Indígena: [Brasília, DF]: Ministério do Esporte, Secretaria Nacional de Desenvolvimento do Esporte e do Lazer, 2005.

SILVA, Carlos Rafael. O Modelo de Gestão Territorializada da Politica de Educação Escolar Indígena no Estado da Bahia. Revista Cadernos de Arte e Antropologia. [on-line]. Vol. 2. 
Pontos de Interrogação, v. 4, n. 2, jul./dez. 2014

Revista do Programa de Pós-Graduação em Crítica Cultural

Universidade do Estado da Bahia (UNEB), Campus II — Alagoinhas - BA

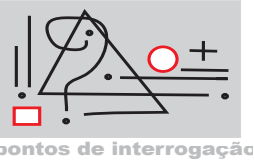

N. 2. 2013. Salvador - Bahia: 2012. Disponível em: <http://www.cadernosaa.revues.org $>$. Acesso em: 15 de dezembro de 2014

Recebido em: 19 de outubro de 2014.

Aceito em: 20 de novembro de 2014. 